\title{
Comparison of Photochemical and Thermal Degradation of Poly (Lactic Acid) Doped by Nanosilver
}

\author{
Maria Mucha* and Sylwia Ksiazek \\ Faculty of Process and Environmental Engineering, Lodz University of Technology, Lodz 90-924, Poland
}

\begin{abstract}
A comparison of thermal and photochemical degradation of poly (lactic acid) film materials (10 $\mu$ m) containing nanosilver are studied by FTIR (Fourier transform infrared) spectroscopy and DSC (differential scanning calorimetry). Rates of thermal and photochemical degradation are determined by measuring the relative changes of absorbance $\left(A_{t} / A_{0}\right)$ of selected bands in PLA (polylactic acid) spectra. Comparison of the effect of both degradation on PLA structure showed that nanosilver act as a stabilizer for photodegradation at $254 \mathrm{~nm}$. As oppose, thermal degradation at $80{ }^{\circ} \mathrm{C}$ indicate, that nanosilver accelerates PLA degradation at the temperature. Glass transition and crystallization/melting processes occurring in PLA and PLA/Ag nanocomposites during both degradation processes were also compared.
\end{abstract}

Key words: Poly (lactic acid), nanosilver particles, nanocomposite, photodegradation, thermal degradation.

\section{Introduction}

Polymer nanocomposites have been an exponentially growing field of research in the development of materials in last few decades. In competition with petroleum-based polymers, PLA (polylactic acid), is one of the most promising candidates for future developments; it is not only biodegradable but also is produced from non-fossil renewable natural resources.

Among the different types of metal nanoparticles that present high potential in fabrication of polymer nanocomposites, e.g., $\mathrm{ZnO}, \mathrm{Ag}, \mathrm{CuO}, \mathrm{TiO}_{2}$ are known for their market antibacterial activity even if the amount of nanoadditives is low [1].

The structure and properties of PLA have been intensively studied [2-7], but it is still a lack of information on its behavior in the presence of silver nanoparticles applied as antibiocidal agent.

PLA outdoor applications in replacing conventional petrochemical-based polymers would be seriously limited because sunlight is the principal source of UV

\footnotetext{
*Corresponding author: Maria Mucha, Specialist, research field: physicochemistry of polymers. E-mail: muchama@wipos.p.lodz.pl.
}

(ultraviolet) irradiation and the degradation of PLA would be strongly accelerated by UV exposure. The knowledge on the effect of short-wavelength radiation on material is very important in such applications because UV is used for sterilization and disinfection.

Therefore, the UV-resistance properties of PLA have to be reinforced for its commercialization of daily products. Usually, chemical absorbing agents are used to improve the UV-resistance properties of plastics, but these chemical compounds are usually toxic to human health and they may migrate during the storage and use of products. Therefore, alternative processes are expected for improving the stability of PLA under UV exposure.

The photooxidation of PLA composites with different types of particles, e.g. organically modified montmorillonite, micro-talc, $\mathrm{TiO}_{2}$, carbon nanotubes were intensively studied last year [8-11].

Thermal stability of PLA, determining its processing and application, is mainly investigated in dynamic conditions [12-21]. It was reported on the base of thermogravimetric analysis that PLA is stable up to about $300{ }^{\circ} \mathrm{C}$ and its thermal decomposition occurs in one stage at $300-400{ }^{\circ} \mathrm{C}$ range. The numerous low-molecular weight degradation products 
such as carbon oxides, cyclic oligomers, acrylic acid, acetone, acetaldehyde and aromatic hydrocarbons were found during thermal fragmentation of PLA by GC-MS (gas chromatography-mass spectrometry) or TG-MS (thermogravimetry coupled with mass spectroscopy) [22, 23]. PLA degradation products are thought to be non-toxic.

It is known that PLA undergoes thermal degradation when heated above its melting point [24]. Nevertheless, there is a lack of information on the behavior of this polymer at elevated constant temperature below melting. Moreover, the thermal stability of PLA nanocomposites with silver is known insufficiently. The silver nanoparticles, exhibiting unique physicochemical properties, added to polymeric matrix yield to biological activity, i.e., antibacterial or/and antifungal properties, particularly needed in medical and pharmaceutical applications $[25,26]$. The great advantage of nanosilver is lack of negative influence on the people health. Moreover, nanosilver particles can be used in optoelectronics, textiles, food packaging, catalysis, sensors, fuel cells, etc..

The aim of this work was to compare the photochemical and thermal degradation of novel PLA films doped with nanosilver. Changes of physicochemical properties of PLA/Ag nanocomposite films have been studied by FTIR (Fourier transform infrared) spectroscopy and DSC (differential scanning calorimetry) analysis.

\section{Experiments}

\subsection{Materials}

Poly (lactic acid) (D-lactate content $<1 \%$ ), was supplied by Hycail (Netherlands). The dichloromethane (pure for analysis, POCh, Poland) was used as the polymer solvent. Nanosilver powder, particles size $<100 \mathrm{~nm}$, organically coated using polyvinylpyrrolidone (for dispersion in polar solvents, less than $0.2 \%$ ), was obtained from Aldrich Chemistry.

\subsection{Preparation of Samples}

PLA/Ag nanocomposites were prepared by repeated mixing (ultrasonic and mechanical) of $4 \%$ (wt) PLA solution in dichloromethane with proper amount of nanosilver particles (previously dispersed in dichloromethane using ultrasounds). Thin polymeric films with thickness of $10 \mu \mathrm{m}$ were obtained by the solution casting method. The obtained films were then carefully dried $4 \mathrm{~h}$ at $50{ }^{\circ} \mathrm{C}$. The weight fraction of silver in the PLA composites was: $0.2 \%$ and $0.5 \%$.

\subsection{Photochemical and Thermal Degradation Conditions}

Thermal degradation was carried out in air atmosphere at $80^{\circ} \mathrm{C}$ up to $40 \mathrm{~h}$. After defined period of degradation time, the polymeric films were systematically analyzed by FTIR spectroscopy and DSC measurements. Photodegradation was carried out under UV lamp produced by BakMed Lodz, type LB-151.1 (emitting $254 \mathrm{~nm}$ radiation) at ambient temperature $\left(25^{\circ} \mathrm{C}\right)$. Maximum time of exposure was $60 \mathrm{~h}$.

\subsection{Methods}

Infrared spectra were recorded by Genesis II FTIR spectrometer (Mattson, USA). For spectra analysis WinFirst software (Mattson) was applied. The absorbances of selected bands was measured and the relative change was calculated.

DSC measurements have been performed at air atmosphere using METTLER FP90 apparatus. The samples were heated with heating rate of $10 \% \mathrm{~min}$. at $30-200{ }^{\circ} \mathrm{C}$ range.

AFM (atomic force microscopy) measurements were done under the ambient air conditions using the Nanoscope III, Digital Instruments (USA) with the silicon nitride tips $\left(\mathrm{SiN}_{3}\right)$. The contact mode was applied. The sensitivity of the tip deviation and the scanner resolution was smaller than $1 \AA$.

Viscometric measurements of PLA dilute solution in dichloromethane were carried out at constant 
temperature $\left(25^{\circ} \mathrm{C}\right)$ using an Ubbelohde viscometer. LVN (limiting viscosity number) was calculated.

\section{Results and Discussion}

Fig. 1 shows an example of AFM photos (recorded as height, phase and amplitude images) of PLA $+1 \%$ Ag nanocomposite. These images indicate the relatively uniform distribution of $\mathrm{Ag}$ nanoparticles within polymeric films but their size varies from few tens to about 100 nanometers. The shape of nanoparticles is generally spherical, however, some of them are non-spherical or form randomly distributed clumps.

\subsection{FTIR Results of Degraded PLA and PLA/Ag Nanocomposites}

During thermal and photochemical degradation of PLA and PLA/Ag film samples the most pronounce changes of absorbance at $1,756 \mathrm{~cm}^{-1}$ (attributed to $\mathrm{C}=\mathrm{O}$ carbonyl band stretching vibrations), and at 1,090 and $1,093 \mathrm{~cm}^{-1}$ (attributed to asymmetric and symmetric stretching vibration of -C-O-C- group) were recorded and analyzed. Furthermore, in a case of photochemical degradation, the clear band at $1,725 \mathrm{~cm}^{-1}$ is formed, suggesting the creation of new carbonyl groups in PLA which is evidence of photolysis process. The additional carbonyl groups are formed at the end chains $(\mathrm{CHO}, \mathrm{COOH})$ or in backbone-resulting of transesterification, which can be inter- or intra-molecular process. On the other hand, FTIR does not allow to detect the products of thermal oxidation in studied samples. Because the transesterification (backbiting) reaction is characteristic at temperatures near melting point and any new absorption peaks were not detected, we suppose that such reaction is negligible in our conditions.

Fig. 2 presents the relative absorbance changes $\left(A_{t} / A_{o}\right)$ of the selected bands of PLA (at 1,756, 1,190 and $1,093 \mathrm{~cm}^{-1}$ ) subjected to the degradation.

It turns out that in early stages of UV exposure, the alterations of spectra in all cases are negligible (induction period). The marked changes appeared after longer time of irradiation. Contrary to thermal degradation, where the degradation is observed immediately after beginning of heating (without any induction period) and the rate of the process is the highest in the first two hours of degradation.

The influence of nanosilver on the rate of changes in the functional groups of PLA is also observed. In a case of photodegradation nanosilver significantly retards PLA photolysis. Ag nanoparticles cause an increase of induction periods of PLA degradation above 2 to 3 times. The results from the fact, which nanosilver particles introduced to PLA absorb $U V$-irradiation and the excitation energy can be dissipated in PLA/Ag nanocomposites or consumed in non-harmful energy transfer processes. It seems also possible that metallic Ag participates in electron transfer to macromolecules, thus it can act as reduction agent $\left(\mathrm{Ag}^{0} \rightarrow \mathrm{Ag}^{+}+\mathrm{e}\right)$, which reacts with photooxidation products. The charge transfer between metal and ligand carbonyl group (so called MLCT (metal-co-ligand charge transfer)) is known
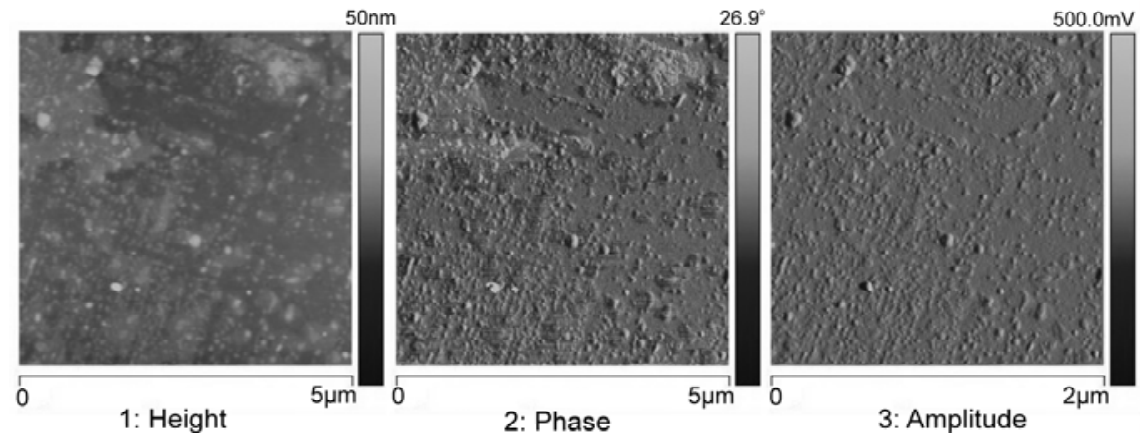

Fig. 1 AFM photos (recorded as height, phase and amplitude images) of PLA + 1\% Ag nanocomposite. 


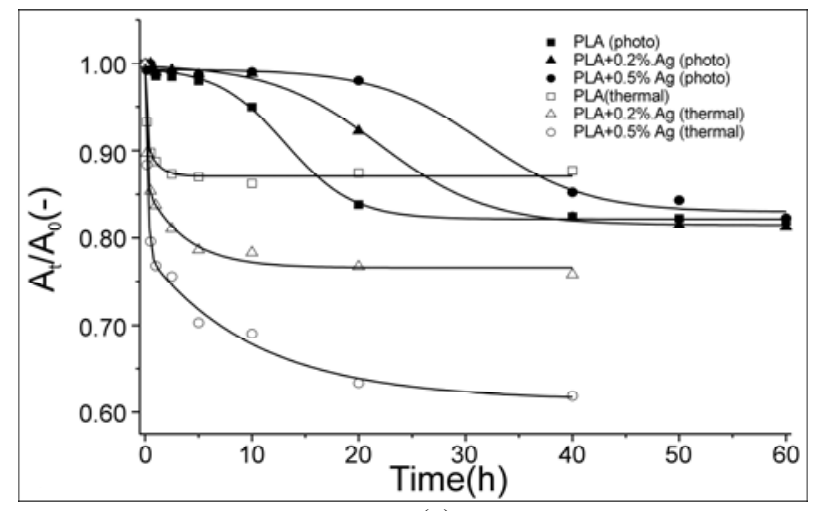

(a)

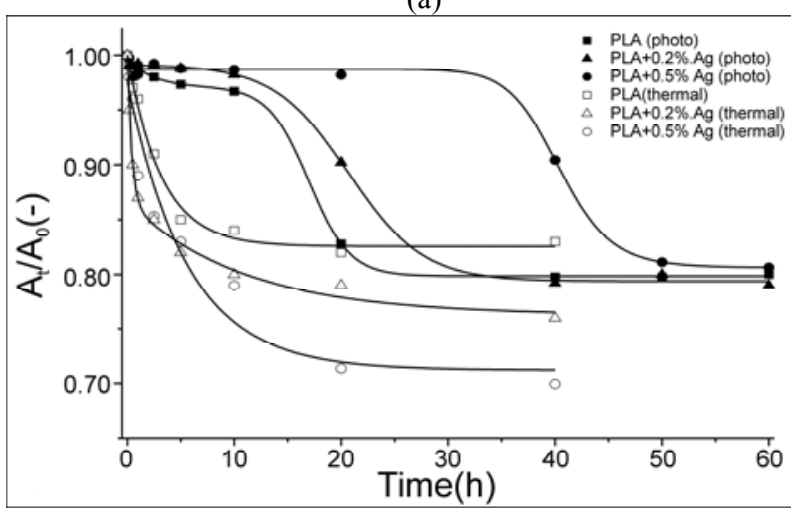

(b)

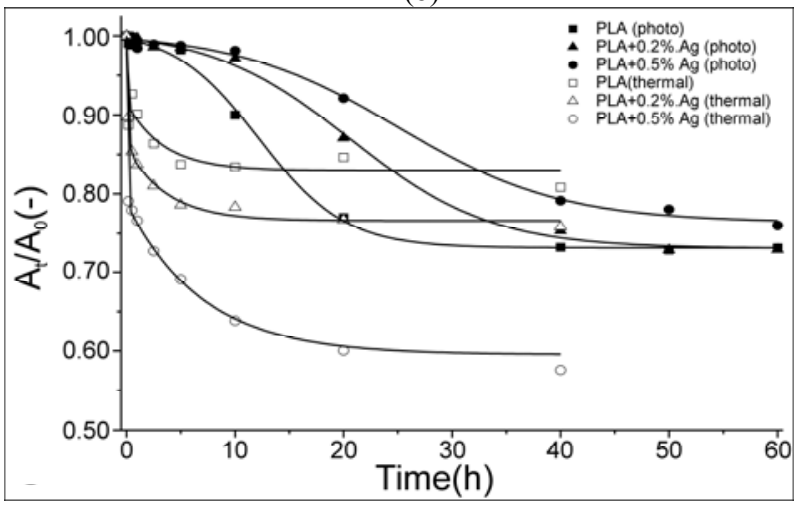

(c)

Fig. 2 Relative changes of absorbance $A_{t} / A_{o}$ of selected bands from FTIR spectra of PLA and its composites with $0.2 \%$ and $0.5 \%$ content of nanosilver: (a) $\mathrm{C}=\mathrm{O}$ (at 1,756 $\mathrm{cm}^{-1}$ ), (b) -C-O-C- (at $1,190 \mathrm{~cm}^{-1}$ ) and (c) -C-O-C- (at 1,093 $\mathrm{cm}^{-1}$ ) versus degradation time; $A_{o}$ and $A_{t}$ are absorbances of undegraded specimen and after $t$-time of degradation, respectively.

in UV-exposed complexes of polymers with transition metals [27].

The opposite effect is observed in thermal degradation. It is clearly seen that nanosilver strongly accelerates thermal degradation of PLA. On the base of FTIR analysis, which showed the lack of new oxidizing products in heated PLA and PLA/Ag composite, we can conclude that $\mathrm{Ag}$ nanoparticles (covered by stabilizer) and embedded in polymer matrix are not able to directly react with oxygen at $80^{\circ} \mathrm{C}$. Although the oxidation does not appear in studied nanocomposites but catalyzing activity of silver nanoparticles is evident. The lack of new products detectable by FTIR indicates that perhaps cyclic compounds (e.g., lactide) are formed resulting of main chain scission. Creation of linear molecules should lead to an increase of end-functional groups.

\subsection{DSC Results of Degraded PLA and PLA/Ag Nanocomposites}

DSC studies of UV-irradiated and thermally degraded PLA and PLA containing 0.5\% Ag nanoparticles were conducted. Fig. 3 present the chosen DSC curves for PLA subjected to photodegradation (a) and thermal degradation (b). All curves exhibit the glass transition temperature (with changing endothermic depression corresponding to relaxation processes), cold crystallization and melting peaks of PLA.

The one broad crystallization peak in the range of $100-130{ }^{\circ} \mathrm{C}$ is typical for PLA analyzed in this conditions [28, 29]. It is named "cold crystallization", which appears not from the melt but from the glassy state.

Interestingly, the single melting peak found in DSC curve for unexposed PLA (at $147.4{ }^{\circ} \mathrm{C}$ ) undergoes splitting in UV-irradiated samples (already after $5 \mathrm{~h}$ exposure). Both peaks $\left(\mathrm{T}_{m 1}\right.$ and $\left.\mathrm{T}_{m 2}\right)$ are not well separated and the difference between their positions on DSC curve is $3^{\circ}-6^{\circ}$. This clearly indicates that at least two different types of crystals exist in UV-irradiated PLA [30]. It can be supposed that photodegradation leads to main chain scission and formation of shorter PLA fragments undergoing moleculear reorganization. Short chains are characterized by higher mobility, thus, this new order of partially decomposed polymer influences the melting process observed by DSC. The double crystalline peaks in PLA were described in 


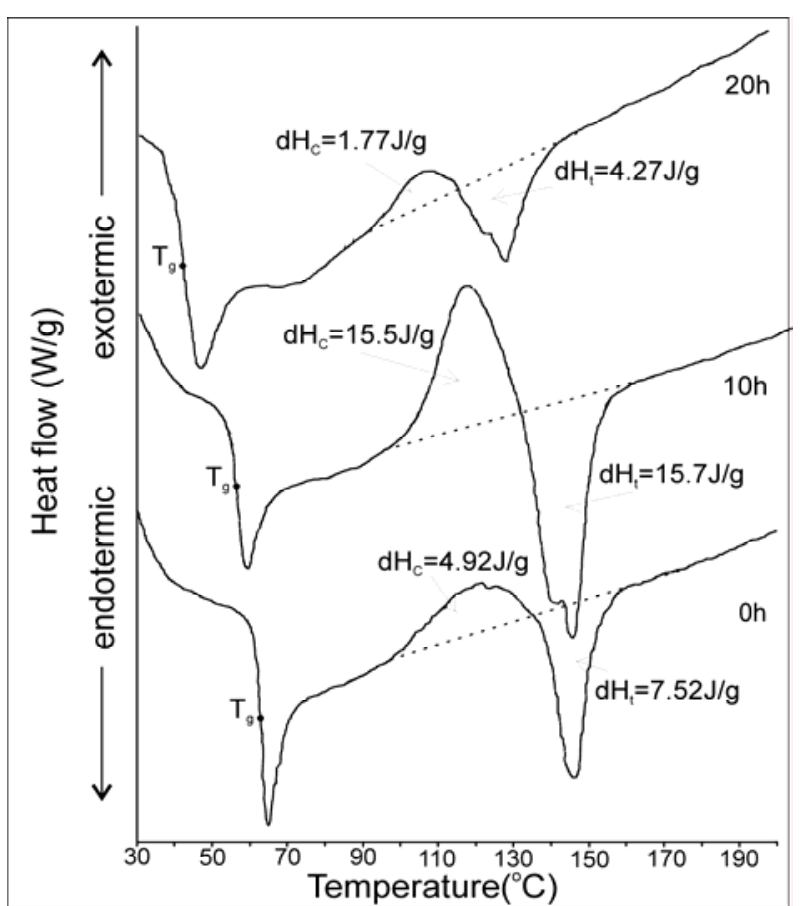

(a)



(b)

Fig. 3 DSC curves of PLA during different time of photodegradation (a) and thermal degradation (b).

literature as corresponding to crystallites of different size, various perfection or stability [31-33].

In a case of thermal degradation, the splitting of melting peak is not observed (Fig. 2b). Relaxation and crystallization peaks gradually disappear after PLA heating degradation. It indicates that polymer undergoes annealing at temperature of $80^{\circ} \mathrm{C}$, in which macromolecules are able to reorganize.

The temperatures of phase transitions $\left(T_{g}, T_{m 1}\right.$ and $\left.T_{m 2}\right)$ crystallinity degree $\left(X_{C}\right)$ in PLA and PLA/Ag composites, obtained from DSC curves, were plotted versus time of photochemical and thermal degradation (Figs. 4 and 5).

It is clear that in a case of both processes the glass transition temperatures of PLA decrease with degradation time (Fig. 4a). In a case of thermal degradation the decrease of $T_{g}$ is linear and small, whenever $T_{g}$ of PLA subjected to UV-irradiation decreases in nonlinear way. Two stages of UV-degradation are observed. First stage, in which the $T_{g}$ changes is minor and it is terminated after $12-13 \mathrm{~h}$ of irradiation (this indicates on induction period). After first stage of UV-degradation the second stage occurs, in which the drop of glass transition temperature is significant.
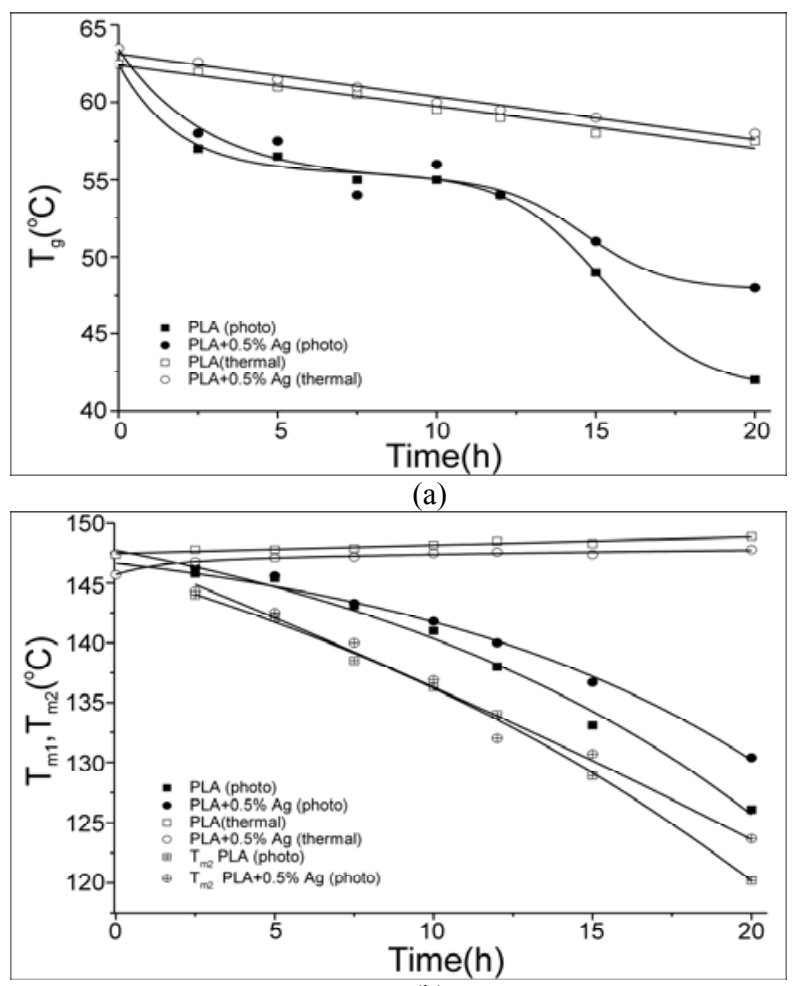

(b)

Fig. 4 Dependence of glass transition temperature, $T_{g}$ (a) and melting temperatures: $T_{m 1}$ and $T_{m 2}$ (b) of PLA and PLA $+0.5 \%$ Ag on degradation time. 


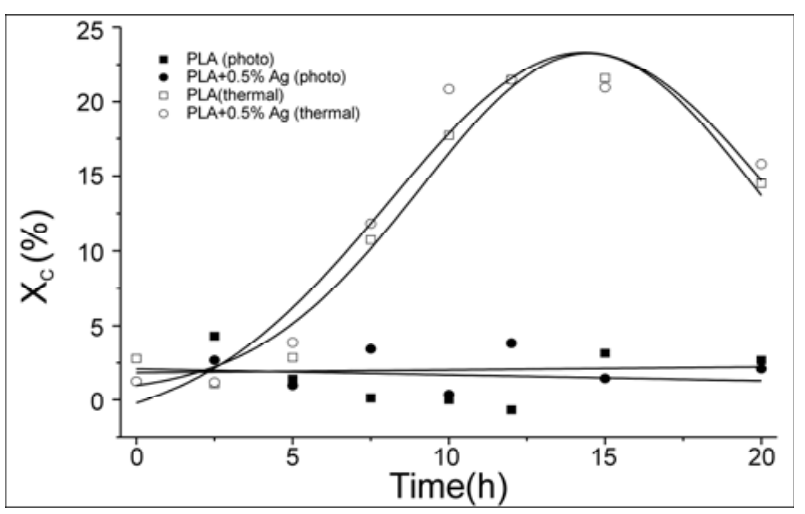

Fig. 5 Changes of crystallinity degree, $X_{C}$ during photochemical and thermal degradation of PLA and PLA + $0.5 \%$ Ag.

UV-irradiation caused the splitting of melting peak (there are two melting temperatures $T_{m 1}$ and $T_{m 2}$ ) due to photoinduced formation of molecular chain scission leading to two crystalline phases of different perfection, contrary to PLA isothermal degradation, where only one melting peak is present $\left(T_{m}\right.$ increases with time of degradation due to annealing process). It means that UV-irradiation leads to more complex processes leading to changes in macromolecule arrangements. It is obviously connected to different mechanism of the both degradations.

Moreover, upon UV-irradiation the decrease of melting temperatures were observed in PLA and its nanocomposites with silver, opposed to thermal degradation where $T_{m}$ rise was found during heating. It indicates that both degrading factors (heat and UV) in a different way influence on macromolecular ordering of PLA.

The crystallinity degree of PLA and PLA in nanocomposite $\left(X_{c}\right)$ (Fig. 5) was calculated from the enthalpies of cold crystallization $\left(\Delta H_{c}\right)$ and melting $\left(\Delta H_{m}\right)$ as follows:

$$
X_{c}=\frac{\Delta H_{m}-\Delta H_{c}}{\left(\Delta H_{m}\right)_{100 \%}} \cdot 100 \%
$$

where, $\left(\Delta H_{m}\right)_{100 \%}$ is the enthalpy of crystallization of a fully crystalline PLA, equal to $93 \mathrm{~J} / \mathrm{g}$ [34].

Initial $X_{c}$ of PLA is very low (close to $1 \%-3 \%$ ). During photodegradation $X_{c}$ does not change. Process of cold crystallization during DSC studies is observed. In a case of thermal degradation heating at $80{ }^{\circ} \mathrm{C}$ causes annealing and reorganization of macromolecules leading to an increase of $X_{c}$ up to $23 \%$. Longer time of thermal degradation leads to the decrease of $X_{C}$ due to destruction of the polymer chain.

Viscosity measurements of dilute solutions indicate on a decrease of molecular mass due to molecular chain scission in both degradations processes. The initial limiting viscosity number of PLA/Ag composites is equal to $84.2 \mathrm{~cm}^{3} / \mathrm{g}$ and is somewhat higher than that for PLA (equal to $80.4 \mathrm{~cm}^{3} / \mathrm{g}$ ). It can suggest that some interactions between PLA and silver nanoparticles are present. Limiting viscosity number of PLA and PLA/Ag is decreased after $20 \mathrm{~h}$ of thermal degradation by about $27 \%$ and similar for photochemical degradation by about $25 \%$.

\section{Conclusions}

Resulting of exposure to UV and high temperature, PLA undergoes random main chain scission and structural changes. Photochemical and thermal degradation was monitored by FTIR spectroscopy but reorganization of macromolecules was proved by DSC analysis.

It was found that nanosilver introduced to PLA restricts its photodegradation, which is probably caused by physical processes of excitation energy transfer or by photoredox reaction between $\mathrm{Ag}$ and polymer or its degradation products. As opposed nanosilver accelerated the thermal degradation of PLA, which has been proved using FTIR spectroscopy.

The differences between the course of photochemical and thermal degradation of PLA and PLA/Ag can be distinguished using DSC. Main alteration was observed in PLA melting process caused by different effect of heat and UV-radiation on macromolecular order.

The modification of PLA by nanosilver allows to obtain the environmentally friendly, biodegradable material with end-use properties such as anti-UV and 
antibacterial effects.

\section{Acknowledgements}

Presented research was financially supported by the Polish National Centre of Sciences under Grant No. UMO-2011/01/B/ST8/06679.

\section{References}

[1] Hajipour, M. J., Fromm, K. M., Ashkarran, A. A., Aberasturi, D. J., Larramendi, I. R.; Rojo, T., et al. 2012. "Antibacterial Properties of Nanoparticles." Trends in Biotechnology 30: 499-511.

[2] Auras, R.; Harte, B., and Selke, S. 2004. "An Overview of Polylactides as Packaging Materials." Macromol Biosci. 4: 835-864.

[3] Belbachir, S. 2010. "Modelling of Photodegradation Effect on Elastic-Viscoplastic Behaviour of Amorphous Polylactic Acid Films." Journal of Mech Phys Solids 58: 241-255.

[4] Madhavan, N. K., and Rajendan, N. N. 2010. "An Overviev of the Recent Developments in Polylactide (PLA) Research.” Bioresour Technol. 101: 8493-8501.

[5] Gupta, B., Revagade, N., and Hilborn, J. 2007. "Poly (Lactic Acid) Fiber: An Overview." Prog Polym Sci. 32: 455-482.

[6] Lim, L. T., Auras, R., and Rubino, M. 2008. "Processing Technologies for Poly (Lactic Acid).” Prog Polym Sci. 33: 820-852.

[7] Rasal, R. M., Janorkar, A. V., and Hirt, D. E. 2010. "Poly (Lactic Acid) Modifications." Prog Polym Sci. 33: 338-356.

[8] Bocchini, S., and Frache, A. 2013. "Comparative Study of Filler Influence on Polylactide Photooxidation." Exp Polymer Lett. 7: 431-442.

[9] Wang, W., Man, C., Zhang, C., Jiang, L., Dan, Y., and Nguen, T. 2013. "Stability of Poly (L-lactide) $/ \mathrm{TiO}_{2}$ Nanocomposite Thin Film under UV Irradiation at 254 nm." Polym Degr Stab. 98: 885-893.

[10] Nakayama, N., and Hayashi, T. 2007. "Preparation and Characterization of Poly (L-Lactic Acid) $/ \mathrm{TiO}_{2}$ Nanoparticle Nanocomposite Films with High Transparency and Efficient Photodegradability." Polym Degrad Stabil. 92: 1255-1264.

[11] Gorrasi, G.; Sorrentino, A. Photo-Oxidative Stabilization of Carbon Nanotubes on Poly (Lactic Acid). Polym Degr Stab. 98: 963-971.

[12] Zou, H., Yi, C., Wang, L., Liu, H., and Xu, W. 2009. "Thermal Degradation of Poly (Lactic Acid) Measured by Thermogravimetry Coupled to Fourier Transform Infrared Spectroscopy." J Therm Ana Calorim. 97:
929-935.

[13] Yussuf, A. A., Massoumi, I., and Hassan, A. 2010. "Comparison of Polylactic Acid/Kenaf and Polylactic Acid/Rise Husk Composites: The Influence of the Natural Fibers on the Mechanical, Thermal and Biodegradability Properties." J Polym Environ. 18: 422-429.

[14] Liu, X.; Khor, S., Petinakis, E., Yu, L., Simon, G., Dean, K., et al. 2010. "Effects of Hydrophilic Fillers on the Thermal Degradation of Poly (Lactic Acid)." Thermochim Acta. 509: 147-151.

[15] Petinakis, E., Liu, X., Yu, L., Way, C., Sangwan, P., Dean, K., et al. 2010. "Biodegradation and Thermal Decomposition of Poly (Lactic Acid)-Based Materials Reinforced by Hydrophilic Fillers." Polym Degrad Stabil. 95:1704-1707.

[16] Yuzay, I. E., Auras, R., Soto-Valdez, H., and Selke, S. 2010. "Effects of Synthetic and Natural Zeolites on Morphology and Thermal Degradation of Poly (Lactic Acid) Composites.” Polym Degrad Stabil. 95: 1769-1777.

[17] Santonja-Blasco, L., Moriana, R., Badia, J. D., and Ribes-Greus, A. 2010. "Thermal Analysis Applied to the Characterization of Degradation in Soil of Polylactide: I. Calorimetric and Viscoelastic Analyses." Polym Degrad Stabil. 95: 2185-2191.

[18] Badia, J. D., Santoja-Blasco, L., Moriana, R., and Ribes-Greus, A. 2010. "Thermal Analysis Applied to the Characterization of Degradation in Soil of Polylactide: II. On the Thermal Stability and Thermal Decomposition Kinetics.” Polym Degrad Stabil. 95: 2192-2199.

[19] Badia, J. D., Santoja-Blasco, L., Martinez-Felipe, A., and Ribes-Greus, A. 2012. "A Methodology to Assess the Energetic Valorization of Bio-based Polymers from the Packaging Industry: Pyrolysis of Reprocessed Polylactide.” Bioresource Technol. 111: 468-475.

[20] Najafi, N., Heuzey, M. C., Carreau, P. J., and Wood-Adams, M. 2012. "Control of Thermal Degradation of Polylactide (PLA)-Clay Nanocomposites Using Chain Extenders." Polym Degrad Stabil. 97: 554-565.

[21] Guo, G. P., Ma, Q. Y., Wang, F., Zhao, B., and Zhang, D. 2012. "Kinetic Evaluation of the Size-Dependent Decomposition Performance of Solvent-Free Microcellular Polylactic Acid Foams." Chinese Sci Bull 57: 83-89.

[22] Kopinke, F. D., Remmler, M., Mackenzie, K., Moder, M., and Wachsen, O. 1996. "Thermal Decomposition of Biodegradable Polyesters-II. Poly (Lactic Acid).” Polym Degrad Stabil. 53: 329-342.

[23] Chien, Y. C., Liang, C., and Yang, S. H. "Exploratory Study on the Pyrolysis and PAH Emissions of Polylactic Acid." Atmos Environ. 45: 23-127. 
[24] Garlotta, D. 2002. "A Literature Review of Poly (Lactic Acid)." J Polym Environ. 9: 63-84.

[25] Chen, X., and Schluesener, H. J. 2008. "Nanosilver: A Nanoproduct in Medical Application." Toxicol Lett. 176: 1-12.

[26] Vasiliev, A. N., Gulliver, E. A., Khinast, J. G., and Riman, R. E. 2009. "Highly Dispersible Polymer-Coated Silver Nanoparticles." Surf Coat Technol. 203: 2841-2844.

[27] Horvath, O., and Srevenson, K. L. 1992. Charge Transfer Photochemistry of Coordination Compounds; $\mathrm{VCH}$ Publishers: New York.

[28] Wang, Y., and Mano, J. F. 2005. "Role of Thermal History on the Thermal Behavior of Poly (L-Lactic Acid) Studied by DSC and Optical Microscopy." J Therm Ana Calorim. 80: 171-175.

[29] Milalloos, R. G., Alexander, K., and Riga, A. 2008. "Investigation of the Interactions between Acidic, Basic, Neutral and Zwitterionic Drugs with Poly-L-Lactic Acid by Thermal and Analytical Method." $J$ Therm Ana
Calorim. 93: 289-294.

[30] Sajjad, S., Huneault, M. A., Li, H., and Park, C. B. 2012. "Poly Lactic Acid Crystallization." Prog Polym Sci. 37: 1657-1677.

[31] Nijenhuis, A. J., Colstee, E., Grijpma, D. W., and Pennings, A. J. 1996. "High Molecular Weight Poly (L-Lactide) and Poly (Ethylene Oxide) Blends: Thermal Characterization and Physical Properties." Polymer 37: 5849-5857.

[32] Kulinski, Z., and Piotrowska, E. 2005. "Crystallization, Structure and Properties of Plasticized Poly (L-Lactide)." Polymer 46: 10290-10300.

[33] Li, J., Chen, D., Gui, B., Gu, M., and Ren, J. 2011. "Crystallization Morphology and Crystallization Kinetics of Poly (Lactic Acid): Effect of N-Aminophthalimide as Nucleating Agent." Polym Bull 67: 775-791.

[34] Fortunati, E., Armentano, I., Iannoni, A., and Kenny, J. M. 2010. "Development and Thermal Behaviour of Ternary PLA Matrix Composites.” Polym Degrad Stabil 95: 2200-2206. 